\title{
Dramatically Growing a Graduate Program: A Seed Investment
}

\section{Dr. Shannon Barker, University of Virginia}

Dr. Shannon Barker completed her PhD at the University of Alabama at Birmingham, and completed two post-doctoral fellowships at the University of Washington and Ecole Polytechnique Federale de Lausanne, specializing in gene delivery. Shannon has been in graduate higher education leadership for six years both at the Georgia Institute of Technology and the University of Virginia, and is currently the Undergraduate Program Director for the University of Virginia's Department of Biomedical Engineering.

\section{Dr. Amy Clobes, University of Virginia}

Dr. Amy M. Clobes is committed to supporting current and future graduate students as Director of Graduate Programs for the University of Virginia School of Engineering and Applied Science. In her current role, Dr. Clobes collaborates to support existing programs and develops new initiatives in graduate student recruitment, training, education, and career and professional development. Dr. Clobes holds a B.S. in Biology from the University of Michigan and Ph.D. in Biomedical Engineering from the University of Virginia. Her combined experience in STEM research and education, program development, and student advising are key to her dedication and success in creating opportunities for graduate students to achieve their education and career goals.

\section{Dr. Jasmine D. Crenshaw, University of Virginia}

Dr. Jasmine D. Crenshaw is the Director of Diversity Programs in the Office of Graduate and Postdoctoral Affairs at the University of Virginia. She collaborates with students, faculty, and staff to establish programs aimed to cultivate a supportive environment for all and recruits diverse community members. She holds a Bachelor of Science in physics from North Carolina A\&T State University and PhD in materials science and engineering from the University of Florida. Her graduate research focused on the self-assembly of Biomolecular motor proteins during active transport for drug delivery applications. Dr. Crenshaw has a keen awareness in the value, purpose, and need for academic support initiatives for students from underrepresented and underserved populations. 


\section{Dramatically Growing a Graduate Program: A Seed Investment}

\section{Introduction}

Enhancing the research enterprise of an institutional entity, in this case an Engineering School with nine different programs, will have great impact on the graduate and undergraduate education within that School, as well as its broader visibility and reputation. The following research mechanistic cycle typically applies to most scientific and technical fields: faculty external funding leads to hiring PhD students, who in turn, generate knowledge and scholarship, which in turn, improves the visibility and reputation of the School, thus resulting in more funded proposals; and the cycle continues. To grow the research enterprise, a School can inflate some part of this process to feed the cycle. One logical insert point for investment is to increase the size of the graduate student body and thus a primary contributing factor to the overall research produced.

Increasing the number of outstanding PhD students is therefore a seed investment. PhD students are critical to the research enterprise, and increasing their numbers has a positive effect on research outcomes with proper mentorship and training. Likewise, the caliber of $\mathrm{PhD}$ student an institution is able to attract is an important factor in a potential faculty member's decision to join. Additionally, $\mathrm{PhD}$ students play a vital role in mentorship of undergraduate students, serving as teaching assistants in courses and as mentors in the laboratory. Graduate students can be particularly influential role models for undergraduates considering research careers. Finally, graduate students that go on to successful careers in a variety of sectors plays a crucial part in expanding the reputation of the School. Their success is a direct reflection of the laboratories and faculty that mentored them.

Just as important as the number of graduate students is the diversity of the student body. The National Science Foundation (NSF), other members of the National Academies, and the US Congress have all spoken to the critical need to cultivate an engineering workforce that represents our entire national population [1-4] By investing in building a robust community of engineers, a school can reap the educational benefits that result from a diverse student body in higher education, where student interactions with those who are different contribute to intellectual self-confidence, engagement, complex thinking, motivation to understand the perspectives of others, citizenship, and motivation to achieve [5-11] These benefits have been shown to translate into the workplace, where diverse teams have been proven to be better able to tackle today's complex societal challenges [12-18].

To this end, the School sought to dramatically grow the $\mathrm{PhD}$ student body using proven best practices in reputation-building, recruitment, and admissions, and the expertise of a variety of School stakeholders, including those from the Graduate Office, Communications, Marketing, Admissions, and Recruitment. A strategic, coordinated, and comprehensive marketing and admissions program was developed, with an overall strategy focused on three primary pillars: A) educating prospective students about the School's world-class research and commitment to diversity and engagement, B) a holistic admission review process, and C) reducing student costs as a burden for both the student and the faculty (Figure 1). This multi-pronged approach yielded significant increases in the size and diversity of the PhD student body, without sacrificing quality. 
Figure 1: Comprehensive Marketing \& Recruitment Strategy

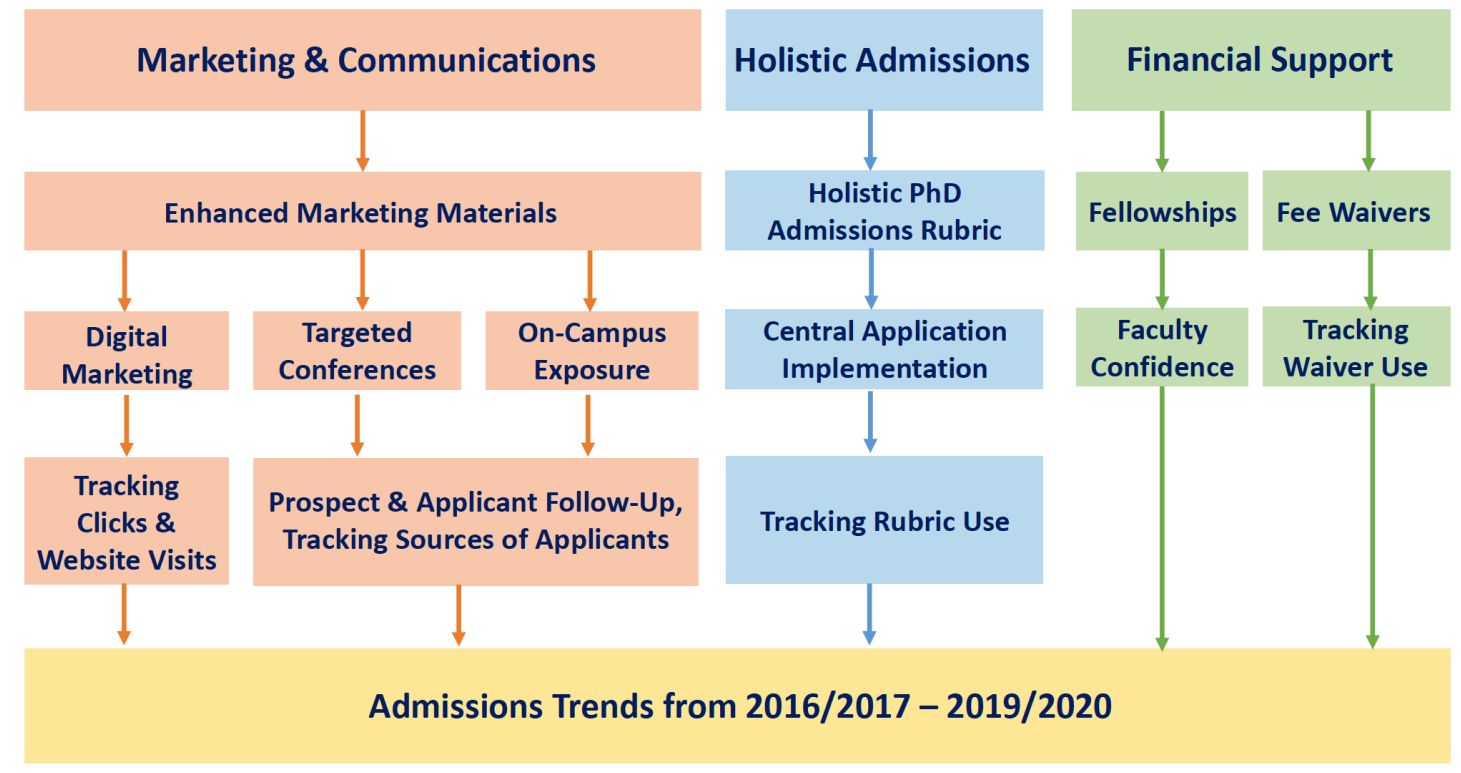

\section{A. Marketing and Communications}

The marketing and communications prong of the overall strategy was developed through a partnership between the School's Communications and Graduate offices, with the overarching goal of reputation-building and increased admissions yield. A proactive recruitment strategy that is deliberate and moving beyond word-of-mouth is critical. Several different strategic tools were utilized, including enhanced marketing materials, digital marketing, targeted conference recruitment, and on-campus events, all based on marketing and recruitment best practices in higher education [19].

\section{Enhanced marketing materials}

A comprehensive overview of marketing materials by the offices of Communications and Graduate Programs was conducted to identify past successful and unsuccessful campaigns and themes. Materials were developed around three primary areas of reputation-building: 1 ) the School's world-class research enterprise, 2) the holistic graduate education curriculum, which includes technical, professional, and career development opportunities, and 3) the School's culture of diversity and engagement. For example, many forms of advertisements were created reflecting the School's resources and support for underrepresented graduate students, an integral component of our overall goal of increasing diversity. Other marketing approaches focused on top questions potential graduate students want answers to, such as how much graduate school will cost. One flyer, labeled "Get Your PhD For Free," laid out funding options for PhD students and ways to obtain them. We were surprised to learn how many undergraduate students were not aware of the funding that comes with getting a $\mathrm{PhD}$ in an engineering discipline, and this flyer generated great interest. All newly developed materials were utilized in each component of the overall strategy, and in other forms of advertisement commonly utilized across higher education (such as ASEE First Bell). 


\section{Digital Marketing}

As marketing of services through digital technologies continues to show success in accelerating product value to consumers (i.e. the value of a particular educational program to prospective students), we enlisted the help of a world-renowned marketing firm with global reach to design two digital marketing campaigns that aid in the overall recruitment plan [20-22]. Two categories of digital market campaigns were developed and implemented: a) one focused on reputationbuilding targeted to undergraduates at top engineering schools, historically black colleges and universities (HBCUs) and other minority-serving institutions (MSIs), and specific international regions; and b) increasing yield after admission offers were made. Both campaigns rely on the creation of engaging ads in multiple formats, and targeting these ads to specific areas, institutions, or individuals. Ads appear in internet browsers, and when clicked, users are taken to a specially developed landing page that includes more information and a prompt to apply. The ads appear in the browsers of the broader audiences mentioned above, but also to individuals who the School has cultivated as prospective students through conferences or on-campus visits. Both campaigns also employ retargeting, whereby once an individual has interacted with our ads, they are specifically targeted for future advertisements. In the yield campaign, all applicants receiving an offer of admission are sent a congratulatory email containing an embedded pixelbased retargeting code, which inserts a cookie in the individual's browser. As today's potential student relies in most part on online interactions, digital marketing ads are an effective means of getting the School's information in front of them in a meaningful way.

\section{Focused Conference Recruitment}

Participation in diversity-focused STEM recruitment fairs have been shown to be effective in recruiting high-quality applicants with prior research experience, and to increase the diversity of the applicant pool [23]. A rigorous conference recruitment schedule was developed with the specific focus of increasing the quantity, quality, and diversity of the graduate student body. The schedule targeted primarily diversity conferences that draw large attendance from multiple engineering disciplines, including the National GEM Consortium, the Society of Women Engineers, the National Society of Black Engineers, the Society of Hispanic Professional Engineers, the Annual Southeastern Association of Educational Opportunity Program Personnel McNair/Student Support Services Scholars Research Conference, and the Black Engineer of the Year Award conference. Additionally, the annual Tau Beta Pi honor society meeting was added. The aim was to build a presence within each organization and society that included not only booth sponsorship, but also larger sponsorship and engagement opportunities, such as ceremonies and poster competitions. It was paramount that current graduate students from the School attended each conference and spent time recruiting prospective applicants. We found these students to be the most effective at communicating the culture of the School in a way prospects could relate to. Additionally, faculty were actively sought out for each conference, as they are the ones prospective students most want speak with.

As a School, the focus was on these larger multi-disciplinary conferences, but additional work within individual programs to recruit at more focused, discipline-specific minority conferences, such as the Annual Biomedical Research Conference for Minority Students and the Grace Hopper Celebration, was carried out. The offices of Communications and Graduate Programs worked with individual programs to design a marketing and recruitment approach tailored to 
each conference, typically sharing marketing materials and offering one staff member to coattend.

Obtaining prospect information is only the first small step in the recruitment strategy. It is fundamental to follow-up with potential applicants in a dynamic and engaging way. At each conference, all prospective students were asked to fill out a digital form that uploaded their information directly into the central application system of the School. This system allows for ongoing communications with the prospect and tracking whether or not they have started an application to the School. Through this system, high-touch communications were regularly sent to each prospect that included information on the culture of the School, available fellowships, and deadline reminders, as well as the ability to upload documents into the central system. Additionally, conference- and year-specific application fee waivers were sent through this system, and their utilization could also be tracked.

As $\mathrm{PhD}$ prospects are most interested in making connections with faculty, follow-up communications included the opportunity to identify faculty of interest. The School forwards this information to individual programs, where student information and any uploaded documents are shared with identified faculty. Faculty are strongly encouraged to then interact with the potential applicant. The School also utilized its Board of Trustees members, many highly accomplished and engaged alumni of the School, to reach out to the top applicants via phone call. Feedback from applicants contacted in this way indicates these recipients were quite impressed and honored to receive the call. For the 2019/2020 admissions cycle, 20 of the 60 applicants called by a Trustee matriculated into the School, and one deferred matriculation for one year. We believe this high-touch approach from the School and faculty is indeed quite powerful.

It should be noted that the School cultivates prospective applicants in other ways as well, including participation in the National Gem Consortium database and the hosting of two REU programs.

\section{On-Campus Exposure}

Though a rigorous and meaningful conference recruitment calendar is important in reputationbuilding and prospect cultivation, focusing solely on fairs may limit the School's ability to make connections with the educators of undergraduate minority students. On-campus recruitment events that introduce prospective students to faculty and current graduate students, demonstrate all the resources available at the School, and highlight the beauty and culture of the region, are an important aspect of the overall strategy [23].

An on-campus recruitment weekend is held each admissions cycle, where prospective domestic applicants are invited to explore the School, the University, and the region. The agenda for this weekend includes a welcome breakfast in an iconic building on campus, one-on-one faculty interviews, lab tours, campus tours, and tours of various regional highlights (such as local winery or historical site). Additionally, prospective students can spend time with current graduate students in a relaxed environment, away from staff and faculty. We find that this allows recruits to ask questions they would not feel comfortable asking faculty or staff, and permits them to dig deeper into the School culture. Finally, a Diversity Social was held during the 2019/2020 
admissions cycle, where all invited recruits, current graduate students, and faculty are invited to a reception focused on the value of diversity and inclusion in the School. Representatives from offices and organizations across the campus who provide resources to underrepresented students are also invited to chat with the prospective students.

In addition to the on-campus recruitment weekends, the School has also hosted an on-campus event, where third and fourth year undergraduate students at HBCUs and MSIs in the region are invited to learn about graduate school and the School itself. The agenda for this one-day event included a welcome breakfast, a session on the value of graduate school, the graduate admissions process, and funding, a resource fair with student organizations and student service, a discussion with a panel of current graduate students, coffee and conversation with faculty, lab tours, and a closing reception. To further build upon potential relationships with these participating institutions, a luncheon was offered whereby institutional administrators and School leadership held a conversation around student needs and possible opportunities for collaboration. Again, attendees were asked to enter their information into the central application system for tracking and follow-up communications, and each attendee received an application fee waiver.

Finally, in order to recruit the School's own outstanding undergraduate students, a special graduate school info session was held for its third- and fourth-year undergraduates, discussing graduate school in general, as well as the benefits of obtaining a graduate degree from the School itself. Additionally, the School's graduate school mentorship program matches interested third year undergraduates with current graduate student mentors. All School undergraduates are also offered an application fee waiver, whether they participate or not.

By developing an overall marketing and recruitment strategy that targets key populations and demographics in a proactive and engaging way, and by implementing a follow-up process that allows for quantitative tracking and high-touch, meaningful interactions, the School can both gauge its approach in real time during the admissions cycle, and work toward meeting its goals of increasing the quantity, quality, and diversity of the $\mathrm{PhD}$ student body.

\section{B. Holistic Admissions Process}

While the communications and marketing prong was focused on increasing the number and diversity of $\mathrm{PhD}$ applications, as well as overall yield, the holistic admissions prong was focused on ensuring that the overall admissions process is effective at admitting students who are likely to succeed and thrive in our $\mathrm{PhD}$ programs. The overarching goal is an admissions process that is holistic, built on evidence-based best practices, and with as little bias as possible.

A multitude of reasons have been raised to account for the higher education achievement gap that persists for individuals from groups historically underrepresented in STEM fields, such as females and ethnic minority groups (specifically African Americans, Hispanics, Native Americans, and Pacific Islanders), including the reliance on traditional quantitative academic metrics, like GRE scores and GPA, used by graduate admissions committees [24-26]. GRE scores have been proven to be a poor indicator of graduate school success time and time again [27-34]. Additionally, research shows that many factors affect GPA beside academic potential, including race, gender, first generation status, high school size, and family income $[28,35]$. Evidence-based best practices have identified other more holistic factors as better indicators of 
graduate school success. Measures of self-efficacy, perseverance, motivation, and belonging have all been linked to completion of degree and achievement, as well as passion for research and prior research experience [23,35-40].

These data and others were used to directly inform the development and implementation of an entirely holistic approach to graduate admissions, one that aims to level the playing field for applicants from all backgrounds and experiences. After gaining a thorough understanding of best practices in graduate admissions, and recognizing faculty need for a relatively efficient means of reviewing large volumes of applicants as fairly as possible, the Holistic $\mathrm{PhD}$ Admissions Rubric was developed. This rubric is comprised of nine criteria, including:

a) Overall letters of evaluation scores

b) Clear demonstration of research potential and vision

c) Clear research goals and interest in solving real-world problems, and alignment of these goals with faculty expertise

d) Clear evidence of motivation, persistence, or the ability to overcome obstacles

e) Evidence of enthusiasm or commitment to research

f) Demonstrated prior research experience in academia and beyond

g) Clear potential for leadership and engagement in academia and beyond

h) Academic preparation for discipline, or the potential to take preparatory courses

i) GPA in major and any noted trends in progression (This one included a tip on consideration of the undergraduate institution when reviewing the GPA, and to look for evidence of an increase in GPA over time.)

These criteria are listed in order of most-predictive of graduate school success to least predictive. GRE scores are omitted from the rubric entirely, and GPA scores are placed last; while evaluator scores, research-related factors, and evidence of persistence and grit are strategically placed in the forefront.

Each criterion is scored a 1, 2, or 3, with descriptive qualifiers for each score on each criterion. Additionally, each criterion includes information on which potential components of the application package can be reviewed to assign a score. For example, for criterion $d$ (clear evidence of motivation, persistence, or the ability to overcome obstacles), the rubric suggests utilizing letters of evaluation, the $\mathrm{CV} /$ resume, the personal statement, and the transcripts for evidence of GPA progression over time; while criterion $f$ (demonstrated prior research experience in academic and beyond) suggests using letters of evaluation, the CV/resume, and the personal statement.

The rubric has undergone several iterations from 2017-2019 based on faculty feedback and a review from two experts in the field of holistic graduate admissions. As PhD admissions are handled predominately through individual programs within the School and their faculty, it was critical that these entities were educated on the predictors of graduate school success and how to identify them in application material. Several faculty dialogue sessions were held over the course of a year, and the rubric was presented for discussion at faculty meetings in each individual program. An Excel form of the rubric was made available to faculty during 2018/2019 admissions cycle. 
To maximize the use of the rubric by faculty and admissions stakeholders, the goal was to make the rubric as easy to use as possible. To that end, the rubric was incorporated into the central admissions system for the 2019/2020 admissions cycle, so that it can be completed real-time while reviewing the application materials, and so its use could be noted within the system for downstream quantitative analysis of overall rubric employment. As a further impetus for rubric use, it was also required that the rubric be completed for any nominee of a School-funded fellowship. This incentive allowed a proof-of-concept so faculty could become familiar with the rubric, hopefully moving beyond its use for only fellowship nominees.

\section{Fellowships and Other Financial Support Structures}

Removal of the socioeconomic barriers to participation in the STEM pipeline can greatly enhance the number of students applying to $\mathrm{PhD}$ programs [23]. Besides ensuring that all prospective students receive an application fee waiver, and highlighting the funding provided to PhD students in all recruitment efforts, the School also aimed to provide a large internal pool of fellowship funds for incoming students, including one for students with a demonstrated commitment to diversity and inclusion, one for the top 5-10\% of the applicant pool, and one allowing faculty to take on a much-needed graduate student while their grant proposals may still be in review. The School also leverages fellowship resources from the NSF Virginia-North Carolina Louis Stokes Advancing Minority Participation Bridge-to-Doctorate Fellowships, the National GEM Consortium, and other institutional fellowships.

\section{Diversity Fellowships}

The School was able to obtain significant competitive funding through the University to cover fellowships aimed at increasing the diversity of the School's graduate student body. $\mathrm{PhD}$ applicants self-nominate for this fellowship through the central application system, and must submit a statement demonstrating their past commitment to the School's five core values, and how they plan to contribute to these values as a graduate student. Nominations are reviewed by a committee of School faculty and staff, and final fellows are selected. The fellowship covers tuition and fees, health insurance, and program stipend, for up to five years of graduate study. Awardees are notified as early as possible in the admissions process.

\section{Academic Merit Fellowships}

Due to funds provided predominately by the State, the School is able to offer 15-20 fellowships each year to the top applicants based on academic merit. This fellowship covers tuition and fees, health insurance, and program stipend for the first academic year. Additionally, the fellowship provides discretionary funds each year through year five of graduate study. Programs nominate their top applicants during the admissions process and a panel of faculty make the final selections. Again, awardees are notified as early as possible in the admissions process.

\section{Safety Net Fellowship}

The School's ability to attract the most outstanding graduate students as soon as they apply is critical toward its overall vision. Based on the timeline of most federal research grants, faculty are not always certain of their financial flexibility during the timing of the admissions cycle, possibly choosing to forgo offering an exceptional student a spot in their lab until they hear the fate of their grant proposal. As most high-quality students are in great demand from multiple 
institutions, the School may miss out on these outstanding students due to the divergent timelines of the grant proposal and admissions processes.

To that end, the School's Advancement office was able to raise funds through a donor-matching mechanism to offer faculty so-called safety net fellowships. These funds are designed to build capacitance into the system, allowing faculty to feel confident in taking on new $\mathrm{PhD}$ students when grants may still be in the pipeline. The funds provide temporary financial support of new students during their first year of graduate study until a time that new grants are administered. It is expected that all student recipients of these funds are transferred to grants as soon as possible, allowing funds to extend as far as possible for recruit future students.

By building up a strong financial support structure for incoming PhD students, the School is able to make offers to top applicants as early as possible, and give faculty the financial freedom to recruit good matches to their program.

\section{Outcomes:}

As individual components of the above described comprehensive marketing, recruitment, and admissions strategy are carried out simultaneously, it is difficult to tease out individual effects on overall admission numbers. The School does, however, employ specific tools to assess each component on its own merits. For example, the marketing firm employed to execute the two digital marketing campaigns performs a great deal of real-time tracking of each campaign's utilization and success by assessing, among other things, impression share trends and clickthrough rates. This information is shared with the School regularly, and is used to adjust ads or targets as needed.

The same is true for conference and on-campus recruitment. Through these efforts, and by participating in national databases, such as the National GEM Consortium, the School cultivates an average of approximately 1,500 prospective graduate applicants each year. Through our central tracking process, we are able to monitor which conferences or sources are yielding the most $\mathrm{PhD}$ applicants to the School and identify best ways to engage with each organization. We are also able to determine the most effective means of follow-up for prospects. For example, we determined that our overall strategy of connecting prospective PhD applicants with faculty of interest was highly successful by analyzing the number of those that took advantage of this opportunity and how many of them went on to apply. When analyzing data from 2018-2019 admissions cycle, $64 \%$ of prospective students cultivated that year through targeted conferences, chose to interact with faculty; and of those that did, $45 \%$ went on to complete an application in the system.

For the purpose of this paper, we will focus on the effects of the entire marketing, recruitment, and admission strategy overall through the analysis of School admission and demographic data over time. The number of applicants, the number of admissions offers made, and the number of matriculating $\mathrm{PhD}$ students was assessed over a four-year period from the 2016-2017 admissions cycle through the 2019-2020 cycle. The comprehensive strategy described above was initially launched in 2016, with some components added in 2017 and 2018. Additionally, through the same period of time, we will analyze the overall demographic makeup of the admissions pool each year, focusing on gender, race/ethnicity, and citizenship. 
Increase in Size of the PhD Student Body

Across the nine individual $\mathrm{PhD}$ programs within the School, a net increase of $48 \%$ was observed in the number of PhD applications submitted from the 2016/2017 cycle through the 2019/2020 cycle (Figure 2), with gains seen in each program with the exception of one (data not shown). These data would seem to indicate that the new aggressive and proactive recruitment and marketing strategies that were initiated within the 2016 calendar year, and fine-tuned the following two years, could be bringing more prospective students into the applicant pool.

Figure 2: Overall PhD Admissions Trends

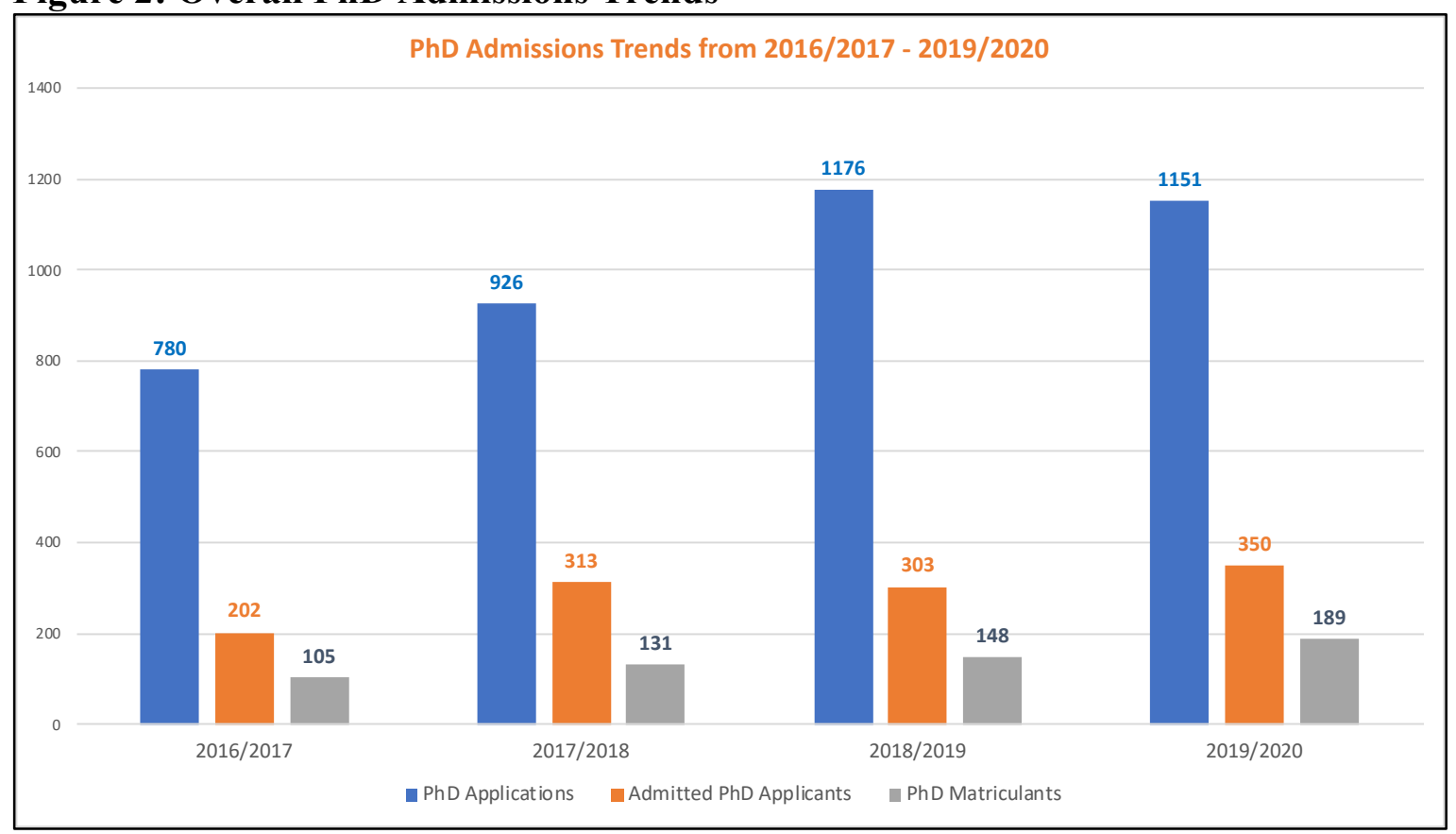

Within the same four-year period, a $73 \%$ increase in the number of $\mathrm{PhD}$ applicants admitted into the School was achieved (Figure 2), a gain that was seen in each and every program (data not shown). The overall percentage of $\mathrm{PhD}$ applicants who were admitted each year stayed roughly the same at between 26- and 34\%. However, the ability for each program to increase the overall number of incoming $\mathrm{PhD}$ students was made possible, we believe, through the significant increase in $\mathrm{PhD}$ student funding, including the academic merit-based, diversity-based, and safety net program fellowships. Faculty and department chairs indicated they felt more comfortable taking on a new student with the confidence they could handle the financial commitment.

These data might suggest the overall marketing and recruitment plan, as well as the new funding paradigm, were structured effectively. The next point of analysis focuses on yield. The number of matriculating PhD students from 2016/2017 to 2019/2020 increased 80\% (Figure 2), with gains seen in each and every program (data not shown). Again, the overall percentage of admitted $\mathrm{PhD}$ applicants who accepted our offer stayed roughly the same at between 42 - and $54 \%$, but the number of matriculants itself increased from 105 to 189 . Several factors can be credited for this yield increase, including the new digital marketing campaign focused on yield, 
the number of fellowships offered, the high-touch prospect and applicant follow-up, and the School's focus on holistic graduate education.

Increase in Diversity of the PhD Student Body

By focusing a significant portion of the overall marketing and recruitment strategy toward underrepresented populations in STEM, by ensuring that the $\mathrm{PhD}$ admissions review process was evidence-based and as free from bias as possible, and by providing additional funding so financial barriers were reduced, an increase in the demographic diversity of the incoming classes of $\mathrm{PhD}$ students was expected. Admission trends over the same four-year period (2016/2017 2019/2020) for specific demographic groups, including gender, domestic underrepresented minorities in STEM, and international applicants, were investigated.

\section{Diversity by Gender}

When analyzing the gender makeup of $\mathrm{PhD}$ applicants over the four years, a $62 \%$ increase in the number of females applying was observed, compared to a $40 \%$ increase in the number of males (and a 48\% increase in the overall number of PhD applicants) (Figure 3). In 2016/2017, females made up $30 \%$ of $\mathrm{PhD}$ applicants, while in $2019 / 2020$, this number had increased to $33 \%$. The percentage of females admitted to the School increased $81 \%$ over those four years, compared to $68 \%$ males (and a 73\% overall increase in $\mathrm{PhD}$ admits). In 2016/2017, females accounted for $37 \%$ of all admitted $\mathrm{PhD}$ applicants, and this number increased to $39 \%$ in 2019/2020. Finally, the incoming class of the $2019 / 2020$ admission cycle was $36 \%$ female, compared to $30 \%$ in 2016/2017. The number of matriculating female PhD students increased $119 \%$ over the fouryear analysis period, while the number of males increased $64 \%$ (compared to an overall $80 \%$ increase in the overall number of matriculating students).

\section{Figure 3: PhD Admissions Trends by Gender}

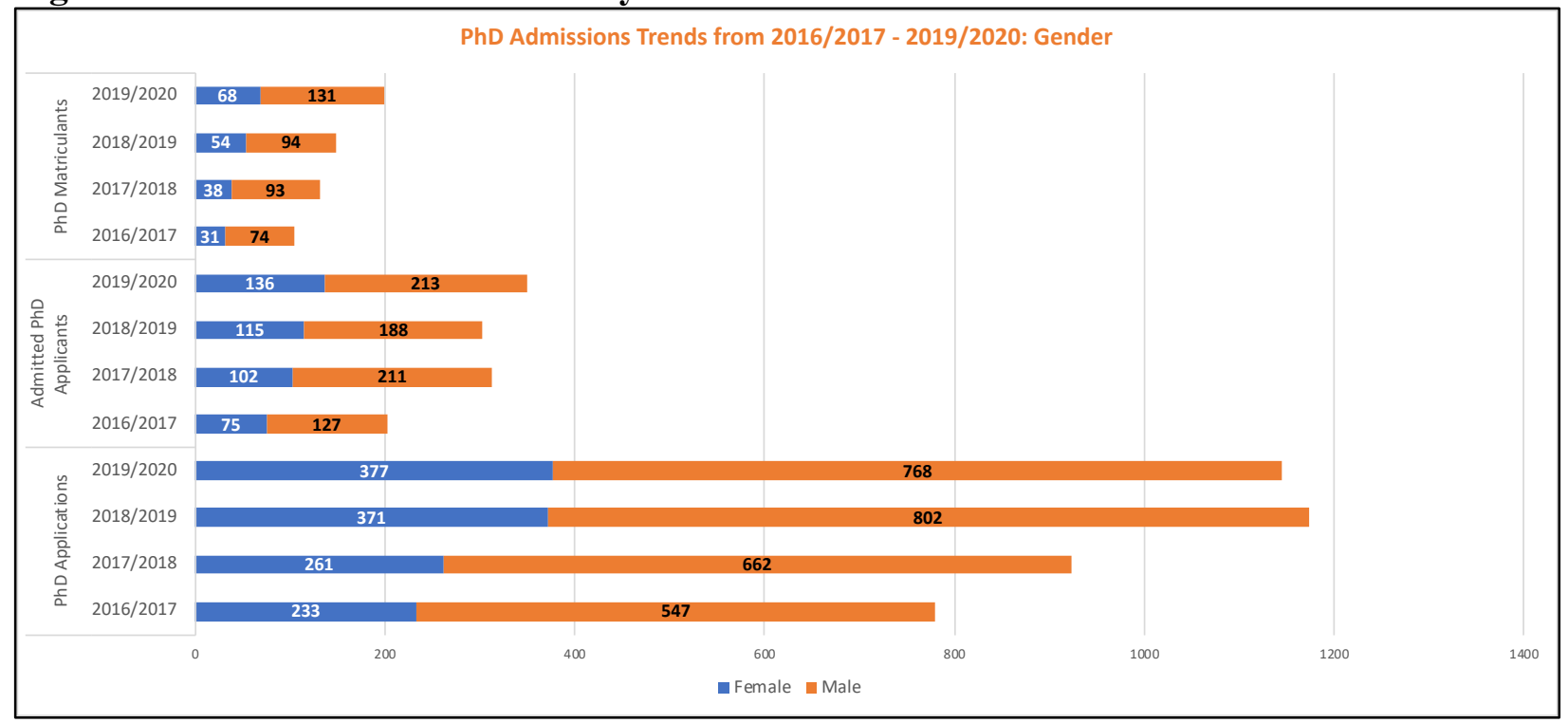

Diversity by Race/Ethnicity

The School also investigated what affect the overall recruitment and admission plan had on the admissions outcomes of domestic (US citizens or permanent residents) individuals who are minorities underrepresented in STEM (URSTEM), as defined by the National Science 
Foundation (African American, Hispanic, and American Indians) [41]. Analysis was limited to domestic students, as racial and ethnic information is not collected in the same manner for international applicants. The data for these minority groups were aggregated here to conform to appropriate data management and reporting norms with overall low sample sizes. Though the numbers of URSTEM PhD applicants, admits, and matriculants are growing, they are however still low. Care should be taken upon interpretation of any increases. The number of domestic URSTEM PhD applicants to the School increased 184\% from 2016/2017 to 2019/2020, compared to an overall increase of $42 \%$ for all domestic applicants (Figure 4). Domestic URMSTEM individuals made up $9 \%$ of the total domestic applicant pool in $2016 / 2017$, and $17 \%$ in $2019 / 2020$.

Figure 4: PhD Admissions Trends by Domestic Race/Ethnicity

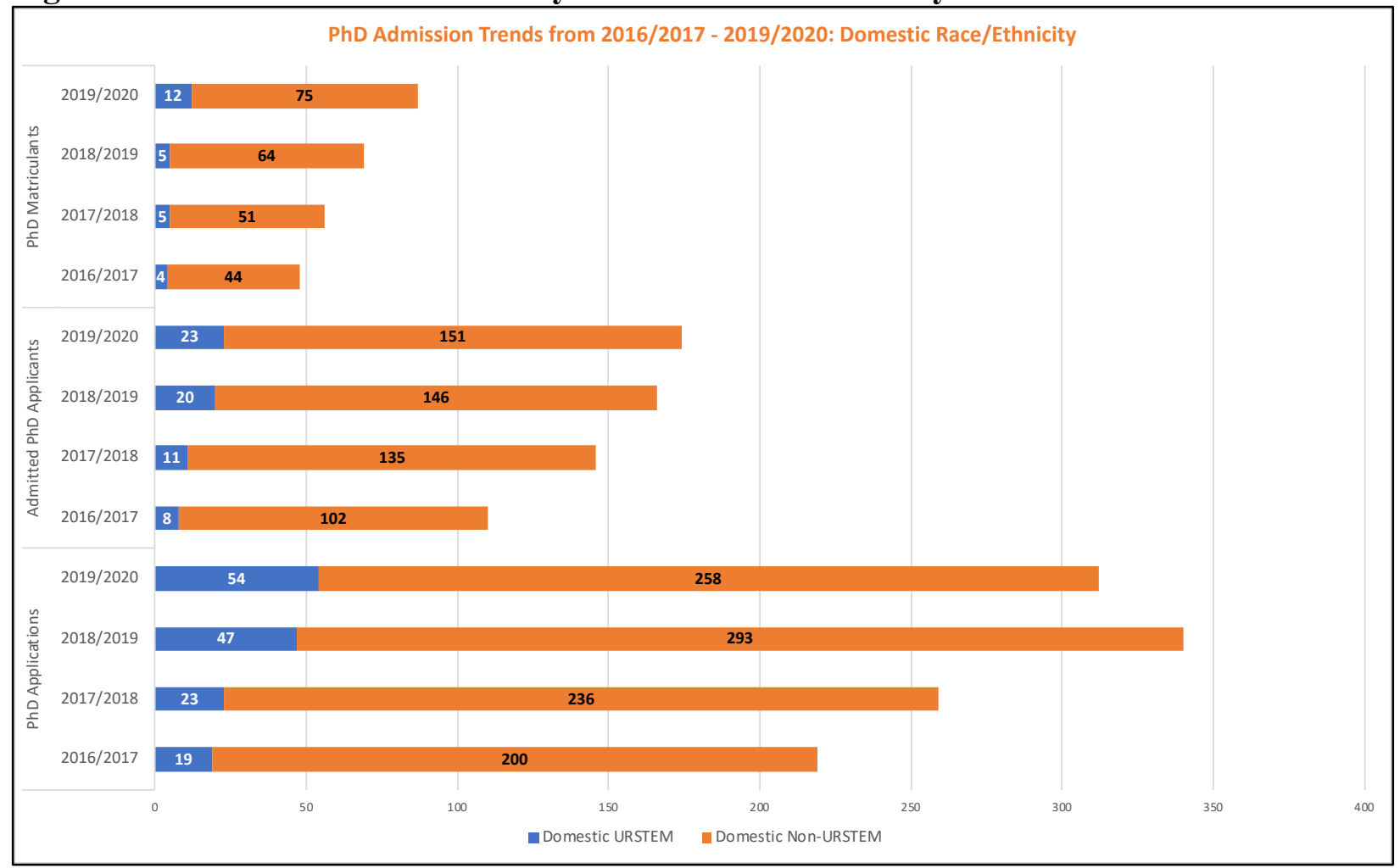

The number of domestic URSTEM applicants admitted to the School increased 188\% over the four years, compared to a $58 \%$ increase in total domestic applicants admitted (Figure 4). Domestic URMSTEM individuals made up 7\% of the total domestic pool of admitted applicants in 2016/2017, and 13\% in 2019/2020. We believe our newly implemented holistic review process, along with the increase in student funding, may have contributed to this increase.

Though a 200\% increase in the number of matriculating domestic URMSTEM students was observed (compared to an $81 \%$ in total domestic students), the actual numbers are very small and much work is still needed in this area (Figure 4). The percentage of the 2016/2017 cohort of domestic $\mathrm{PhD}$ students was $8 \%$, compared to $14 \%$ in 2019/2020. Though we have made great progress in encouraging URMSTEM students to apply, and our faculty have begun to admit significantly more of these applicants than in previous years, building trust with the URSTEM 
community takes time and commitment. We did see great gains in the 2019/2020 domestic URSTEM yield, and we hope to keep building on this success moving forward.

\section{Diversity by Citizenship}

When analyzing gains in admission data for international applicants, increases in $\mathrm{PhD}$ applicants, admits, and matriculants that mirror the gains in the overall increases could again be observed (Figure 5). This trend is significant to note given the widespread reporting of application decreases across graduate programs from international populations [42-45]. For this School, the number of international applicants increased 50\% over the four-year period, compared to a $42 \%$ growth in domestic applications. Admitted international $\mathrm{PhD}$ applicants increased 91\%, compared to a $58 \%$ domestic increase. Finally, the number of matriculating international students grew $79 \%$, while growing $81 \%$ for domestic students.

\section{Figure 5: PhD Admissions Trends by Citizenship}

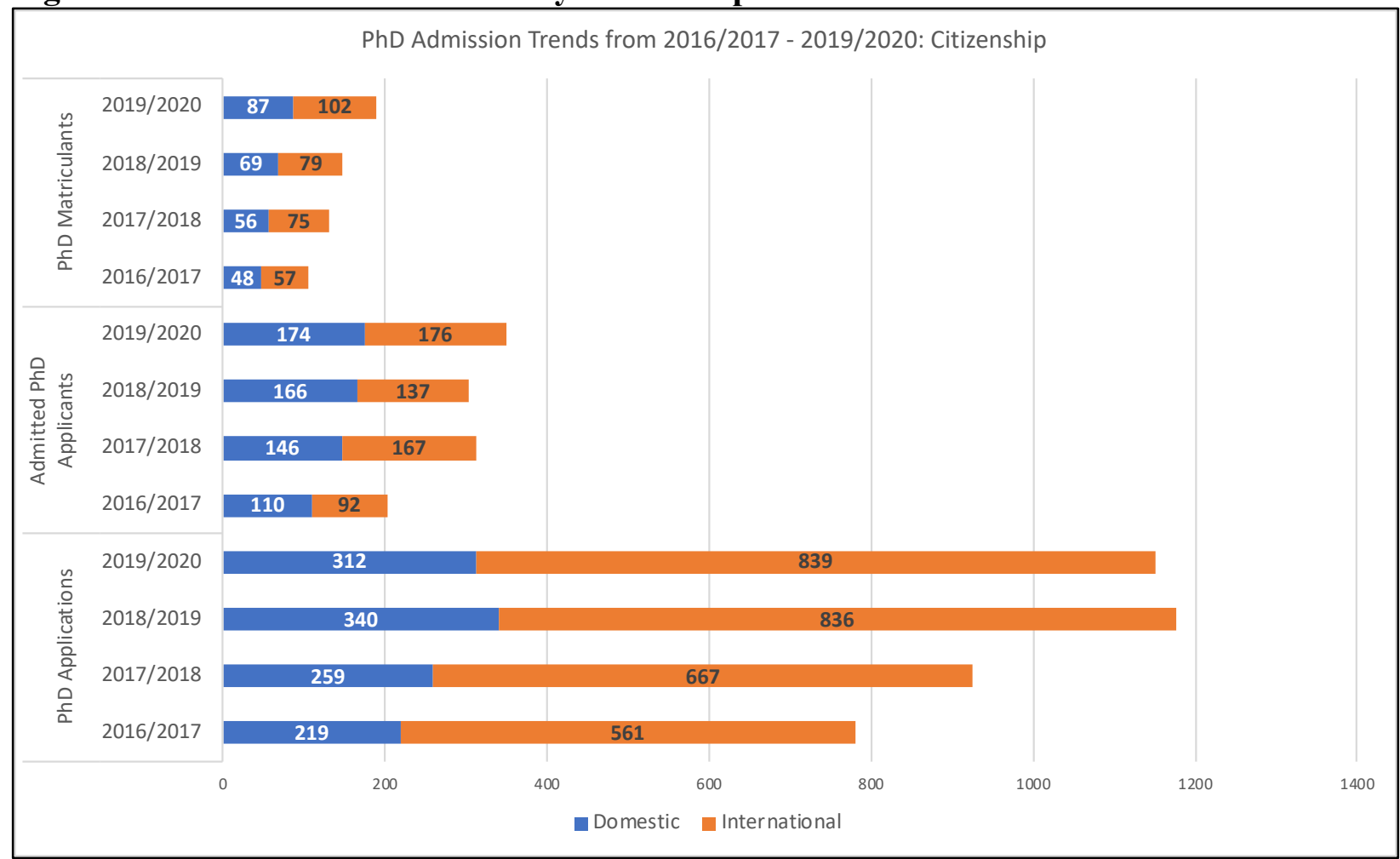

When looking specifically at what percent international applicants were represented in these categories, no overall growth was seen. The percentage of international PhD applicants remained between $71 \%$ and $73 \%$ from $2016 / 2017$ to 2019/2020. Likewise, the percentage of international admitted applicants held steady from between $45 \%$ and $53 \%$; and the percentage of matriculants between $53 \%$ and $57 \%$.

\section{Discussion}

Recognizing that a flourishing $\mathrm{PhD}$ program is an integral component of an institution's research enterprise and overall reputation, the School embarked on a mission to increase the number, quality, and diversity of its graduate student body. School leadership was committed to achieving these goals, prioritizing financial and personnel resources toward its development and 
implementation. The resulting proactive, evidence-based, and comprehensive strategy was implemented initially in 2016, with modifications made throughout the four years of assessment described above. During these four years, dramatic growth was seen in the number of $\mathrm{PhD}$ applications submitted, the number of applicants admitted, and the size of incoming PhD cohorts. These impressive gains pushed the School into the number one ranking for the highest rate of growth in PhD student enrollment from 2015 to 2018 among top-50 US engineering schools.

This period of growth correlates with double-digit increases in the School's sponsored research funding, which increased by 75\% between fiscal years 2016 and 2019, placing the School well above the average research growth rate for top engineering graduate schools. This boom in the research enterprise is of course due to a variety of innovative and forward-thinking endeavors implemented by School leadership toward building a more robust research infrastructure. And quality $\mathrm{PhD}$ students working alongside world-class faculty is a key component of that infrastructure. It should be noted the number of School faculty with research and/or teaching roles increased 30\% from 2014 to 2019.

Of course, the School recognizes the responsibility it bears with such dramatic increases in graduate student numbers. Proper funding and personnel are needed to ensure all students are fully supported, as well as its educational objectives. School leadership, faculty, and support staff all worked diligently to create an educational environment that is rigorous, holistic, and inclusive. Great care has been taken to develop robust professional and career development opportunities for graduate students. Likewise, a strong network of emotional and personal support structures has been developed and implemented specifically for this student body.

Though, as stated above, much work needs to be done to increase the diversity of the graduate student body, we did see great gains in both the overall numbers of female and URSTEM applicants, admitted applicants, and matriculants, and the percentage of these populations relative to the total pool. The School has a demonstrated commitment to diversity, inclusion, and engagement, where students, faculty, and staff all work together to foster an environment where everyone's perspectives and lived experiences are not only accepted but believed to be vital to solving today's complex challenges. The School already has the top US graduation rate for undergraduate African American, Asian, Hispanic, and multi-racial engineering students, and recently became one of the first institutions to earn a bronze award from the ASEE Diversity Recognition Program. The School is especially proud of its support of female engineers in the STEM pipeline. The total graduate enrollment was 32\% female in 2019 , well above the national average of $26 \%$ [46]. It is also conducting its own research analyzing the achievement gaps between minority and majority students, and what interventions actually work to close these gaps. By communicating these successes and others, a reputation of inclusivity and studentcentered support can be fostered, with the potential to synergistically improve the overall recruitment and admissions strategy.

Much work remains to be done to further analyze the success of the overall approach. For example, use of the Holistic PhD Admissions Rubric by faculty, and the correlation of its use to overall demographic admission trends, needs to be assessed. Is the rubric serving its intended purpose? Are faculty comfortable using it? Is its utility changing the demographic makeup of our graduate student body, and eliminating bias? Is the rubric effectively identifying students 
that have the most potential to succeed in graduate school? Assessing first-year GPA, time-toproposal, time-to-degree, retention, and other metrics will be critical.

Furthermore, more careful analysis of the correlation between increased $\mathrm{PhD}$ student numbers and overall research enterprise can be undertaken. What trends can be observed in publication numbers, funded grant proposals, and overall faculty productivity? Do faculty indeed believe that having more students in their labs has improved the quality and quantity of their work?

It is also fundamentally important to understand how the dramatic growth in student numbers has affected the cultures of the individual laboratories, programs, and the School overall. Do students still feel they have open-door access to support when needed? An assessment of whether the resources available to these students are adequate, and whether new or different approaches are needed, will provide vital information to School leadership and inform the overall strategy.

In the end, the School has been able to achieve its initial goals of growing and diversifying the $\mathrm{PhD}$ program along with its research enterprise. Understanding that investing in these young researchers not only increases the amount of research performed, but in fact elevates it, has been the center of this successful approach. The School's success over the years to come will be defined in great part by these students.

\section{References}

1. "Broadening participation at the National Science Foundation: A framework for action," National Science Foundation, p. 1-52, 2008

2. "Broadening participation in America's STEM workforce," Committee on Equal Opportunities in Science and Engineering Biennial Report to Congress 2011-2012, August 2013

3. "Rising above the gathering storm: Energizing and employing America for a brighter economic future," National Academy of Sciences, National Academy of Engineering, Institute of Medicine, Washington DC, 2007

4. "Expanding underrepresented minority participation: America's science and technology talent at the crossroads," National Academy of Sciences, National Academy of Engineering, and Institute of Medicine, Washington DC, 2011

5. W.B. Harvey, "American council on education (ace), minorities in higher education twentyfirst annual status report (2003-2004)," American Council on Education, 1-100, 2005

6. P. Gurin, E.L. Dey, E.L. Hurtado, Gurin, P., "Diversity and higher education: Theory and impact on educational outcomes," Harvard Educational Review, 72, 330-366, 2002

7. P. Gurin, B.R.A. Nagda, G.E., "The benefits of diversity in education for democratic citizenship," Journal of Social Issues, 60(1), 17-34, 2004

8. A.L. Antonio, M.J. Chang, K. Hakuta, D.A. Kenny, S. Levin, \& J.F. Milem, J. F. "Effects of racial diversity on complex thinking in college students," Psychological Science, 507-510, 2004

9. J. Ferrini-Mundy, "Science education: Driven by diversity," American Association for the Advancement of Science 340:278, 2013

10. S.E. Page, "The difference: How the power of diversity creates better groups, firms, schools, and societies," Princeton NJ, Princeton University Press, 2008 
11. L. Hong, S.E. Page, "Groups of diverse problem solvers can outperform groups of highability problem solvers," Prod Natl Acad Sci USA 101:16385, 2004

12. A. Antonio, (2001), "The role of interracial interaction in the development of leadership skills and cultural knowledge and understanding," Research on Higher Education, 42, 593617,2001

13. C. Ozgen, P. Nijkamp, J. Poot, "The elusive effects of workplace diversity on innovation," Papers in Regional Science, 96:S29-S49, 2017

14. K.K. Moon, R.K. Christensen, "Realizing the performance benefits of workforce diversity in the US federal government: the moderating role of diversity climate," Public Personnel Management, 2019, https://doi.org/10.1177/0091026019848458

15. A.Y. Suharnomo, S. Wahyudi, "A systematic literature review of managing workplace diversity for sustaining organizational competitive advantage," International Journal of Mechanical Engineering and Technology, 8(12):398-406, 2017

16. C.A. Poodry, "Minorities in the chemical workforce: Diversity models that work (A workshop report to the Chemical Sciences Roundtable)," Washington DC: National Academies Press, 2003

17. S.T. Bell, A.J. Villado, M.A. Lukasik, L. Belau, A.L. Briggs, "Getting specific about demographic diversity variable and team performance relationships: A meta-analysis," Journal of Management 3: 709-743, 2011

18. O.C. Richard, T. Barnett, S. Dwyer, K. Chadwick, "Cultural diversity in management, firm performance, and the moderating role of entrepreneurial orientation dimensions," Academy of Management Journal 47:255, 2004

19. J. Quarterman, "An assessment of barriers and strategies for recruitment and retention of a diverse graduate student population," College Student Journal 42(4):947, 2008

20. O. Zervine, Y. Stukalina, "Developing a marketing strategy for a higher education institution in the agenda of customer-driven education," International Conference on Reliability and Statistics in Transportation and Communication, 2018, https://doi.org/10.1007/978-3-030$12450-2 \quad 73$

21. J.M. Pharr, "Best practices in digital content marketing for building university brands," Association of Marketing Theory and Practice Proceedings 2019, p 8, 2019 https://digitalcommons.georgiasouthern.edu/amtp-proceedings 2019/8

22. D. Vrontis, B. Bassum, S. El Nemar, C. Themistocleous, "The impact of digital marketing as compared to traditional marketing's impact on university-bound students," International Studies of Management and Organization, ISSN 1558-0911, 2019

23. M.A. Wilson, A.L. DePass, A.J. Bean, "Institutional interventions that remove barriers to recruit and retain diverse biomedical PhD students," CBE Life Sci Educ 17(2):ar27, 2018

24. M. Kuo, "Student performance measures that don't perform," Science Magazine, 2017

25. Council of Graduate Schools, Holistic review in graduate admissions. Washington DC: Council of Graduate Schools, 2016

26. J.R. Posselt, L.M. Garces, "Expanding the racial diversity and equity agenda to graduate education," American Journal of Education 120:443, 2014

27. C. Miller, K. Stassun, "A test that fails," Nature 510:303-304, 2014

28. L. Moneta-Koehler, A.M. Brown, K.A. Petrie, B.J. Evans, R. Chalkley, "The limitations of GRE in predicting success in biomedical graduate school," PLoS One 12(1), e0166742, 2017

29. C. Wolf, "The effect of the Graduate Record Examination on minority applications: Experience at New York Institute of Technology," Journal of Allied Health 4: e65-67, 2014 
30. P.S. Cahn, "Do health professions graduate programs increase diversity by not requiring the Graduate Record Examination for admission," Journal of Allied Health 1:51-56, 2015

31. K. Powell, "On the lookout for true grit," Nature Careers, 504:471, 2013

32. FairTest, "Examining the GRE: Myths, Misuses, and Alternatives", 2007, www.fairtest.org/facts/gre.htm.

33. S, Jaschick, "An unlikely campaign to move beyond GRE scores," Inside Higher Ed., 2016

34. www.ets.org/gre/institutions/scores/guidelines/board guidelines.

35. J.D. Hall, A.B. O'Connell, J.G. Cook, "Predictors of student productivity in biomedical graduate school applications, " PLOS One, 2017

36. "Essential Guide to Graduate Admissions," Council of Graduate Schools, Washington DC. CGS, 2012

37. R. McGee \& J.L. Keller (2007), "Identifying future scientists: Predicting persistence into research training," CBE Life Sci Educ 6:316, 2007

38. "Holistic admissions in the health professions: Findings from a national survey," Urban Universities for HEALTH, Washington DC, 2014

39. J.D. Kent, M.T. McCarthy, "Holistic review in graduate admissions," Council of Graduate Schools, Washington DC, 2016

40. M.N. Bastedo, N.A. Bowman, K.M Glasener, J.L. Kelly "What are we talking about thwn we talk about holistic review? Selective college admissions and its effects on low-SES students," Jounral of Higher Education, 89(5), 782, 2018

41. "Survey of Earned Doctorates: U.S. citizen and permanent resident doctorate recipients, by race/ethnicity and broad field of study: Selected years, 1990-2010," National Science Foundation, Division of Science Resources Statistics, Table 22, Arlington, VA, 2011

42. L. Jackson, "International graduate-student enrollments and applications drop for $2^{\text {nd }}$ year in a row," The Chronicle of Higher Education, Feb 7, 2019

43. E. Redden, "Number of enrolled international students drop," Inside Higher Education, Nov 18,2019

44. C Woolston, "International applications to US graduate programmes are still declining," Nature, Feb 12, 2019

45. S. Wood, "Sharp international student decline costs US, study finds," Diverse Education, Aug 8, 2019

46. J. Roy, "Engineering by the numbers," American Society of Engineering Education, 2019 